Article

\title{
Improving Asphalt Mixture Performance by Partially Replacing Bitumen with Waste Motor Oil and Elastomer Modifiers
}

\author{
Sara Fernandes ${ }^{1}$, Joana Peralta ${ }^{2}$, Joel R. M. Oliveira ${ }^{1}$ (D), R. Christopher Williams ${ }^{3}$ and \\ Hugo M. R. D. Silva ${ }^{1, *}$ \\ 1 CTAC, Centre for Territory, Environment and Construction, University of Minho, 4800058 Guimarães, \\ Portugal; id4966@alunos.uminho.pt (S.F.); joliveira@civil.uminho.pt (J.R.M.O.) \\ 2 Wacker Chemical Corporation, 6870 Tilghman Street, Allentown, PA 18106-9346, USA; \\ Joana.Peralta@wacker.com \\ 3 Department of Civil, Construction and Environmental Engineering, Iowa State University, \\ Ames, IA 50011-3232, USA; rwilliam@iastate.edu \\ * Correspondence: hugo@civil.uminho.pt; Tel.: +351-253-5102-00
}

Received: 21 July 2017; Accepted: 2 August 2017; Published: 5 August 2017

Featured Application: This work deals with the partial substitution of asphalt binder with waste motor oil and elastomer modifiers in order to obtain improved mixtures for pavement application purposes, which is also compared to an alternative mixture using bio-oil. The featured application of this solution is the production of new asphalt binders and mixtures for paving works in general.

\begin{abstract}
The environmental concern about waste generation and the gradual decrease of oil reserves has led the way to finding new waste materials that may partially replace the bitumens used in the road paving industry. Used motor oil from vehicles is a waste product that could answer that demand, but it can also drastically reduce the viscosity, increasing the asphalt mixture's rutting potential. Therefore, polymer modification should be used in order to avoid compromising the required performance of asphalt mixtures when higher amounts of waste motor oil are used. Thus, this study was aimed at assessing the performance of an asphalt binder/mixture obtained by replacing part of a paving grade bitumen (35/50) with $10 \%$ waste motor oil and $5 \%$ styrene-butadiene-styrene (SBS) as an elastomer modifier. A comparison was also made with the results of a previous study using a blend of bio-oil from fast pyrolysis and ground tire rubber modifier as a partial substitute for usual PG64-22 bitumen. The asphalt binders were tested by means of Fourier infrared spectra and dynamic shear rheology, namely by assessing their continuous high-performance grade. Later, the water sensitivity, fatigue cracking resistance, dynamic modulus and rut resistance performance of the resulting asphalt mixtures was evaluated. It was concluded that the new binder studied in this work improves the asphalt mixture's performance, making it an excellent solution for paving works.
\end{abstract}

Keywords: waste motor oil; styrene-butadiene-styrene; bitumen modification; bio-binder; asphalt mixtures; performance

\section{Introduction}

Currently, there is a growing concern to reuse waste materials and to conserve or minimize the use of natural resources in road paving. Thus, many studies have recently emerged in which these issues, or part of them, are discussed [1-3]. Under this assumption, the study of new asphalt binders that partially incorporate wastes is essential to reduce the use of bitumen directly obtained from oil 
sources, which is important for the sustainable development of road paving construction. Some studies related to this matter refer to non-petroleum binders [4] and synthetic binders made up of used oils, resins and polymers [5].

One example of a bitumen substitute or asphalt rejuvenator that has been studied lately is bio-oil, mainly produced from fast pyrolysis of biomass materials [6,7]; i.e., renewable organic matter, namely from agriculture, forestry or urban wastes. Bio-oil behavior at intermediate and high temperatures is similar to that of a conventional bitumen [8], but it is too stiff, and is quite brittle at low temperatures. However, that problem could be solved by adding ground rubber from used tires (GTR) in order to obtain a bio-binder with a very good performance [9].

The incorporation of waste motor oil in asphalt mixtures is also being tested to prevent aging, or as a bitumen rejuvenator $[10,11]$, due to its lower viscosity, which results in lower mixing and compaction temperatures $[12,13]$. This solution is also environmentally friendly, because waste motor oil is not totally recyclable [14]. However, the addition of waste motor oil could bring some disadvantages for asphalt mixture performance, namely a reduced elastic recovery and rutting resistance [15]. Thus, polymer modification should be used to minimize some of these problems, and the elastomer styrene-butadiene-styrene (SBS) could be considered the most suitable modifier [16] of bitumen after addition of waste motor oil. In fact, SBS increases the asphalt mixtures rutting resistance at high temperatures and cracking resistance at low temperatures, and it also improves the tensile strength and elastic recovery properties of bitumen [17].

Taking into account that bio-oil from fast pyrolysis was not available in the necessary amounts for road paving works in several countries because this technology is not used globally at an industrial scale, this work focused on studying an alternative solution using waste motor oil to partially replace the amount of bitumen used in asphalt mixtures. Therefore, an asphalt mixture was produced with a bitumen modified with waste motor oil and SBS, and its performance was evaluated and compared with a conventional control mixture produced with $35 / 50$ bitumen, and with the mixture previously studied by Peralta et al. [6] with bio-oil and ground rubber.

This new binder can be seen as a sustainable solution for road paving works, because both the economic and environmental criteria are being considered, as suggested by other authors $[18,19]$. In fact, by reducing the amount of bitumen used in asphalt mixtures, a high amount of waste materials can be used, with a consequent reduction in the global cost of the mixtures. However, the asphalt mixture produced with this new binder must perform as well as a conventional mixture produced with a current bitumen in order to ensure real advantages in a comprehensive way, and this factor is assessed in this work.

\section{Materials and Methods}

The materials and methods used in this study were selected to compare the results with those previously obtained by Peralta et al. [6] using bio-oil and ground rubber, with the necessary adjustments for the European region.

\subsection{Materials}

The materials used for production of the new asphalt binder in this study are those presented below:

- Conventional bitumen (B35/50) supplied by Cepsa Portugal (located in Matosinhos, Portugal);

- Styrene-butadiene-styrene (SBS) elastomer, supplied by Indústrias Invicta S.A. (located in Porto, Portugal), with a maximum size of $4 \mathrm{~mm}$; and

- Waste motor oil (MotorOil) from heavy vehicles supplied by Correia \& Correia (located in Sertã, Portugal), without any kind of treatment. 
Additionally, the following aggregate fractions were selected from Bezzeras quarries (located in Guimarães, Portugal), in order to obtain an asphalt concrete mixture (AC 14 surf) for surface layers of road pavements:

- Fraction $0 / 4$ of crushed granite with a nominal maximum aggregate size (NMAS) of $4.0 \mathrm{~mm}$;

- Fraction $4 / 6$ of crushed granite with a NMAS of $6.3 \mathrm{~mm}$;

- Fraction 6/14 of crushed granite with a NMAS of $14.0 \mathrm{~mm}$; and

- Limestone filler with a NMAS of $0.125 \mathrm{~mm}$.

It should be noted that the final aggregate gradation of the AC 14 surf mixture is quite similar to that used by Peralta et al. [6] (with 9.5 mm NMAS), which allows their direct comparison. Primarily, they had been used as the main type of mixtures applied in surface layers in both regions where the studies were developed.

\subsection{Experimental Procedure}

The experimental work developed in this study was divided into two main phases of production and characterization:

- The initial phase of production and testing of the asphalt binders (conventional bitumen B35/50 and new binder with waste motor oil and SBS), and

- The final phase of production and testing of the asphalt mixtures (conventional mixture with B35/50 bitumen and asphalt mixture with the new binder).

\subsubsection{Production and Testing of Asphalt Binders}

The production of the binder partially replaced with waste motor oil and SBS was carried out by adding $10 \mathrm{wt} \%$ waste motor oil and $5 \mathrm{wt} \%$ SBS to the base bitumen (B35/50), as concluded in a previous work [20]. A low shear mixer (IKA RW 20 equipment, IKA ${ }^{\circledR}$-Werke GmbH \& Co. KG, Staufen, Germany) was used to obtain an initial blend of the materials at a temperature of $180{ }^{\circ} \mathrm{C}$. Then, the binder was placed in a high shear mixer (IKA T 65 D ULTRA-TURRAX equipment, IKA ${ }^{\circledR}$-Werke $\mathrm{GmbH} \& \mathrm{Co}$. KG, Staufen, Germany), at a speed of $7200 \mathrm{rpm}$ for $20 \mathrm{~min}$ at $180^{\circ} \mathrm{C}$ in order to obtain a homogeneous blend.

After production, Fourier transform infrared (FTIR) spectroscopy tests were performed to assess the differences and the interaction between the materials used to produce the new binder developed in this work. FTIR spectra can be a very useful tool for the analysis of the macromolecules of the studied materials, because various organic chemical components [15] can be identified. The equipment used was a Jasco FT/IR-6600 (Jasco, Easton, MD, USA) with a range of wave numbers from $4000 \mathrm{~cm}^{-1}$ to $400 \mathrm{~cm}^{-1}$ with 32 scans.

Then, rheology tests were performed in a dynamic shear rheometer (DSR) model 81-PV6002 (Controls, Milan, Italy), according to EN 14770 [21], in order to obtain the stiffness master curve and the high temperature performance grade of the new binder, which was compared to the conventional bitumen B35/50 applied in road paving.

Finally, the viscosity of the binders at very high production temperatures was evaluated with a Brookfield viscometer model DV-II+ (AMETEK Brookfield, Middleboro, MA, USA), according to EN 13302 [22], in order to define the mixing and compaction temperatures to be used in the production of asphalt mixtures in the following phase of this work.

It should be noted that the binder properties obtained in these tests will also be compared to those obtained in the previous study using the asphalt binder with bio-oil and ground tire rubber (GTR) from cryogenic milling (Lehigh Technologies, Tucker, GA, USA) [6]. To produce this material, the bio-oil was initially blended with $15 \mathrm{wt} \%$ cryogenic GTR at a speed of $3000 \mathrm{rpm}$ for $1 \mathrm{~h}$ at $110{ }^{\circ} \mathrm{C}$, resulting in a cryogenic rubber modified bio-oil (cryoMBO). This blend ( $20 \mathrm{wt} \%)$ was later added to a PG64-22 bitumen (Seneca Petroleum, Des Moines, IA, USA), at a speed of $3000 \mathrm{rpm}$ for $20 \mathrm{~min}$ at 
$120^{\circ} \mathrm{C}$, so as to obtain the modified asphalt binder. The low temperatures used in these processes were due to the sensitivity of bio-oil to higher production temperatures.

Some additional basic characteristics of the bitumen modified with waste motor oil and SBS, like the penetration and ring and ball values, can also be found in a previous study [20].

\subsubsection{Production and Testing of Asphalt Mixtures}

Concerning the asphalt mixtures studied in this work, with conventional B35/50 bitumen and with the new binder (combining motor oil and SBS), the same optimum binder content of $5.0 \%$ resulted from using the European Marshall mix design method [23,24]. These mixtures were designed for a heavy traffic level, higher than 10 million equivalent standard axle loads (ESAL), and thus Marshall specimens were compacted with 75 blows per side.

As previously mentioned, the production and compaction temperatures of both asphalt mixtures were based on Brookfield viscosity results (as discussed in Section 3.1). Specimens prepared for performance tests were produced to meet the target value of $4.0 \%$ air voids.

However, each mixture was designed according to the current practice of each country where the studies were developed. Thus, the asphalt mixture with bio-oil and GTR described in the previous study [6], which will be used for comparison purposes, was manufactured with a binder content of 5.5\%, using the US SuperPave mix design methodology [25]. The production and compaction temperatures of that mixture with bio-oil and GTR were $150{ }^{\circ} \mathrm{C}$ and $140{ }^{\circ} \mathrm{C}$, respectively, in order to meet the same air void target value of $4.0 \%$ for that mixture.

After producing the asphalt mixtures, their performance was assessed with the following tests, selected to allow a direct comparison between all materials studied:

- Water/moisture sensitivity according to the standard AASHTO T 283-07 [26];

- Fatigue cracking resistance according to the standard AASHTO T 321-07 [27]; and

- Stiffness modulus in accordance with the standard AASHTO TP 79-10 [28].

Finally, the rutting resistance of the asphalt mixtures studied in this work was evaluated with the wheel tracking test, according to EN 12697-22 [29] standard. The triaxial repeated loading test [28] was used in the previous study of the asphalt mixture with bio-oil and GTR [6] in order to assess its rutting resistance, namely by assessing the accumulated strain values. Despite the different standards used, which do not allow a direct comparison, they evaluate the same property and have the same base concepts. Thus, an indirect comparison will be carried out concerning this property.

\section{Results and Discussion}

\subsection{Asphalt Binder Test Results}

First, the differences between the binder materials were analyzed by using FTIR tests, and the corresponding results can be observed in Figure 1.

The FTIR spectra show the chemical transformations/interactions that may or may not have occurred during asphalt binder production. The main absorbance peaks of the spectra of all asphalt binder materials occur in the same wavenumber ranges $\left(700-1800 \mathrm{~cm}^{-1}\right.$ and $\left.2800-3050 \mathrm{~cm}^{-1}\right)$ because the results are mainly controlled by the conventional base bitumens. This means that the main functional groups of the conventional base bitumens (B35/50 and PG 64-22) are also present in the modified binders with waste motor oil and SBS (B35/50 \& MotorOil \& SBS) and with bio-oil and ground rubber (PG64-22 \& cryoMBO).

The spectrum of rubber modified bio-oil (cryoMBO) is slightly different from those of asphalt binder materials, mainly due to the presence of some moisture in the bio-oil [6].

Nevertheless, it was concluded that the new modified binders can be a good alternative to conventional bitumens, because they are chemically similar and/or compatible. 


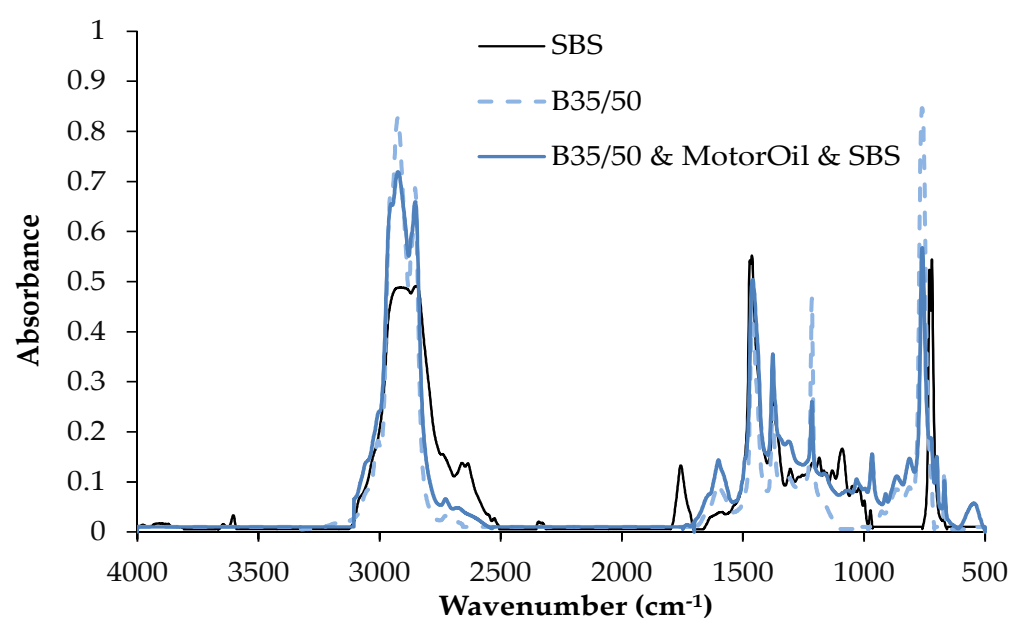

(a)

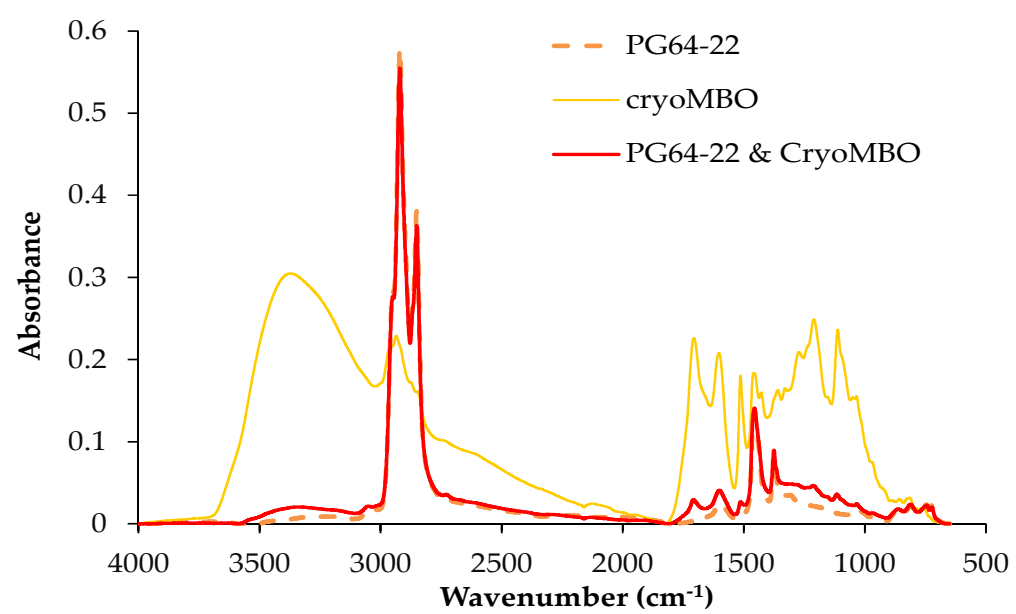

(b)

Figure 1. Fourier transform infrared (FTIR) spectra results of: (a) styrene-butadiene-styrene (SBS) elastomer, conventional bitumen (B35/50) and modified asphalt binder B35/50 \& MotorOil \& SBS; (b) Rubber modified bio-oil (cryoMBO), bitumen PG64-22 and modified asphalt binder PG64-22 \& cryoMBO (adapted from Peralta et al. [6], @ AAPT, 2014).

The rheology of the asphalt binder materials was then evaluated with a dynamic shear rheometer (DSR), by carrying out frequency sweep tests at different temperatures. The stiffness master curves obtained with those tests are presented in Figure 2.

The master curve of the modified binder with motor oil and SBS (B35/50 \& MotorOil \& SBS) shows a lower slope than that of conventional bitumen (B35/50), which may be associated with a low susceptibility of this binder to frequency and temperature changes. On the other hand, the rheological behavior obtained in the previous study with bio-binder (CryoMBO) [6] showed that it is comparable to conventional bitumen (PG64-22) and the modified binder (PG64-22 \& cryoMBO), because all these materials present master curves with very similar shapes. The different behavior of the new binder developed in this study (B35/50 \& MotorOil \& SBS) may be related to the higher amount of elastomer (SBS) used, in comparison with the ground rubber amount (3\%) used in the bio-oil study.

The rheological results were also used to calculate the high temperature continuous performance grades of all asphalt binders, which are presented in Table 1 . The addition of 10\% waste motor oil and 5\% SBS clearly increased the performance grade of the base bitumen B35/50, mainly due to the high amount of elastomer used. In turn, in the past study with bio-oil [6], 20\% bio-binder (cryoMBO) was added to the base bitumen (PG 64-22), almost without changing its high temperature 
performance grade. Thus, the rheological results indicate that the new binder developed in this work (B35/50 \& MotorOil \& SBS) is rheologically or mechanically superior to the conventional bitumens and the modified binder PG64-22 \& cryoMBO, particularly at high service temperatures, indicating its suitability for asphalt road pavements applied in hot climate zones.

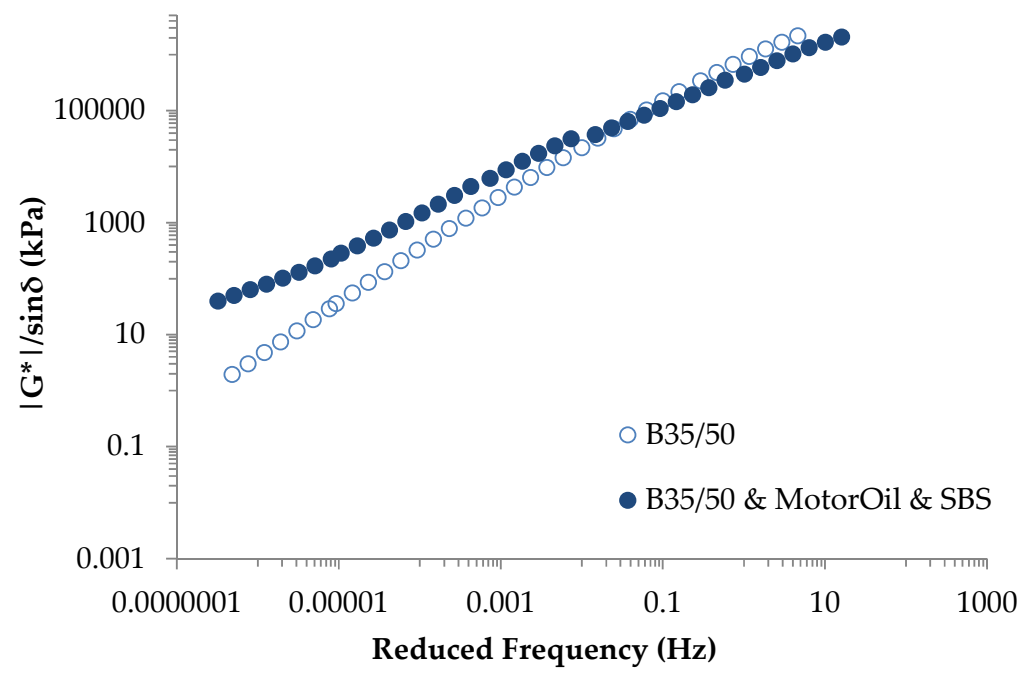

(a)

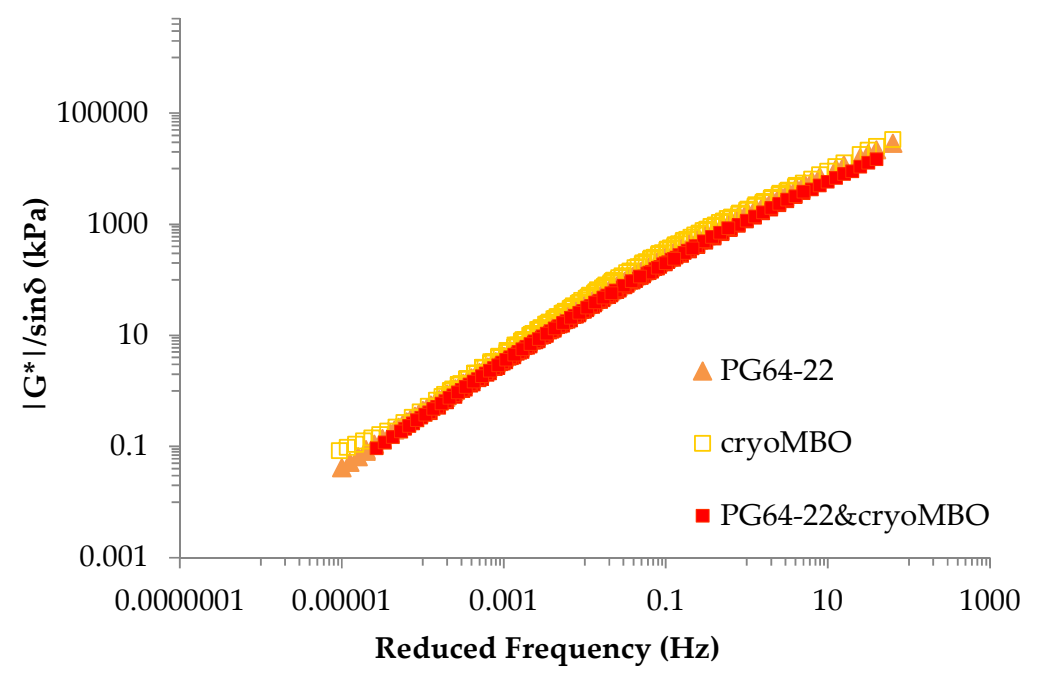

(b)

Figure 2. Stiffness master curves $\left(\mathrm{T}_{\text {ref }}=20^{\circ} \mathrm{C}\right.$ ) results of: (a) bitumen $\mathrm{B} 35 / 50$ and modified asphalt binder B35/50 \& MotorOil \& SBS; (b) CryoMBO, bitumen PG64-22 and modified asphalt binder PG64-22 \& cryoMBO (adapted from Peralta et al. [6], @ AAPT, 2014).

Table 1. High temperature continuous performance grade of conventional bitumens (B35/50 and PG 64-22), rubber modified bio-oil (CryoMBO) and modified asphalt binders (B35/50 \& MotorOil \& SBS and PG64-22 \& cryoMBO).

\begin{tabular}{cc}
\hline Materials & High Temperature Continuous Performance Grade $\left({ }^{\circ} \mathrm{C}\right)$ \\
\hline Conventional bitumen (B35/50) & 65.1 \\
Modified asphalt binder (B35/50 \& MotorOil \& SBS) & 76.8 \\
Conventional bitumen (PG 64-22) & 66.6 \\
Rubber modified bio-oil (CryoMBO) & 61.3 \\
Modified asphalt binder (PG64-22 \& cryoMBO) & 65.5 \\
\hline
\end{tabular}


Finally, taking the ideal viscosity values for mixing and compaction [30] into account, it was possible to define the optimum temperatures for asphalt mixture production in the next phase of the work. In the case of the asphalt binder with motor oil and SBS, the mixing and compaction temperatures for asphalt mixture production were determined to be $180^{\circ} \mathrm{C}$ and $160{ }^{\circ} \mathrm{C}$, respectively, while those temperatures were $160^{\circ} \mathrm{C}$ and $140^{\circ} \mathrm{C}$ for the conventional asphalt mixture with $\mathrm{B} 35 / 50$ bitumen. The new binder presented mixing and compaction temperatures higher than expected. This may be caused by the SBS particle effect, which greatly increases the viscosity of this binder, although waste motor oil has decreased the viscosity before interaction with SBS modifier.

\subsection{Asphalt Mixtures Tests Results}

In relation to the water or moisture sensitivity of the studied asphalt mixtures, both in Europe and the US, a minimum tensile strength ratio (TSR) of 70\% is recommended [31], although some conservative agencies refer to a TSR value of $80 \%$ [32-34]. The novel asphalt mixture studied in this work, with waste motor oil and SBS, showed a TSR value of $80 \%$, which narrowly meets the recommended values to assure the needed durability of this mixture. In the previous study with bio-oil and ground rubber [6], the asphalt mixture presented a TSR value of $84 \%$, which is also greater than $80 \%$, and thus that mixture also fulfilled the requirements.

Subsequently, the results of the fatigue cracking resistance test are summarized in Figure 3, namely for the new asphalt mixture with waste motor oil and SBS (B35/50 \& MotorOil \& SBS), the conventional mixture with B35/50 bitumen, and also for the asphalt mixture with bio-oil and ground rubber (PG64-22 \& cryoMBO). Those results show the variation in the number of loading cycles $\left(\mathrm{N}_{\mathrm{f}}\right)$ before fatigue failure of each mixture (defined through the reduction of the stiffness to half of its initial value) as a function of the tensile micro strain $(\mu \varepsilon)$ applied in the fatigue test.

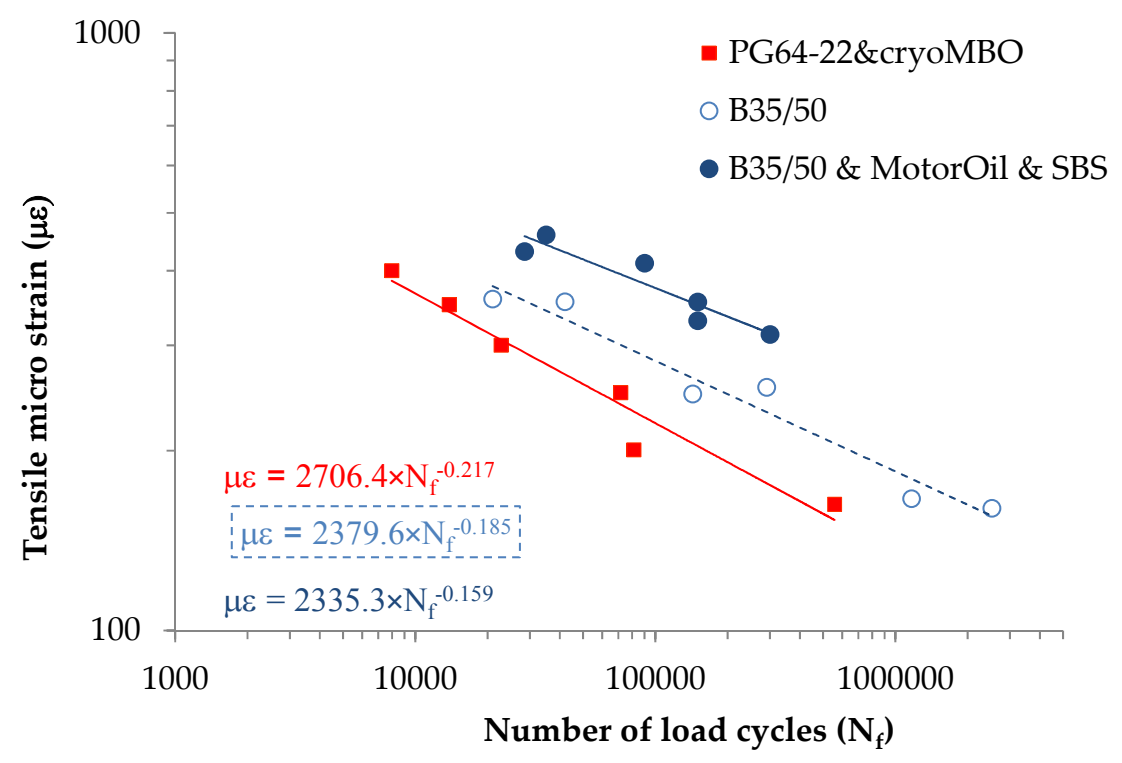

Figure 3. Variation in the number of loading cycles $\left(\mathrm{N}_{\mathrm{f}}\right)$ before fatigue failure with the tensile micro strain $(\mu \varepsilon)$ applied in the fatigue test for the studied mixtures.

Those results demonstrate that the new asphalt mixture with waste motor oil and SBS (B35/50 \& MotorOil \& SBS) is more resistant to fatigue than the conventional asphalt mixture (B35/50), at least in the range of the tensile strain values used in this test. The low viscosity of the waste motor oil and the high amount of SBS elastomer used may justify the very good fatigue cracking resistance of this new mixture. The asphalt mixture with bio-oil and ground rubber from the previous study [6] presented a 
lower fatigue resistance, probably due to the higher stiffness of the bio-binder or the lower amount of ground rubber used.

One of the main models used to predict the fatigue life of an asphalt mixture in road pavements was that proposed by Shell [35]. The fatigue laws obtained for both modified asphalt mixtures (with waste motor oil and SBS or with bio-binder and GTR) indicate a fatigue life higher than that computed by the Shell model for an asphalt mixture with $4000 \mathrm{MPa}$ and an asphalt volume content of $12 \%$, which confirms the suitable fatigue performance of those mixtures. Moreover, the experimental fatigue coefficients $K_{1}$ and $K_{2}$ mentioned by other authors [36] were determined to be $5 \times 10^{-14}$ and 5.171 for the conventional asphalt mixture with B35/50 bitumen. The new mixture with $10 \%$ motor oil and 5\% SBS presented fatigue coefficients of $K_{1}=1 \times 10^{-14}$ and $K_{2}=5.508$, while the mixture with bio-binder and GTR presented fatigue coefficients of $K_{1}=1 \times 10^{-11}$ and $K_{2}=4.368$. In conclusion, both mixtures with modified binders (B35/50 \& MotorOil \& SBS and PG64-22 \& cryoMBO) showed an adequate fatigue performance, at least similar to that that of the conventional asphalt mixture.

The stiffness modulus of asphalt mixtures is a very important parameter for road pavement design, and it also influences the mixture fatigue performance. Figure 4 shows the master curves of the dynamic stiffness modulus of the several asphalt mixtures studied in this work for a reference temperature of $21^{\circ} \mathrm{C}$. In order to obtain these master curves, the conventional mixture with B35/50 bitumen and the asphalt mixture with waste motor oil and SBS were tested at $0,10,20$ and $30{ }^{\circ} \mathrm{C}$, according to the current practice [3], while the asphalt mixture with bio-oil and ground rubber was tested at 4,21 and $37^{\circ} \mathrm{C}$, following another procedure [37].

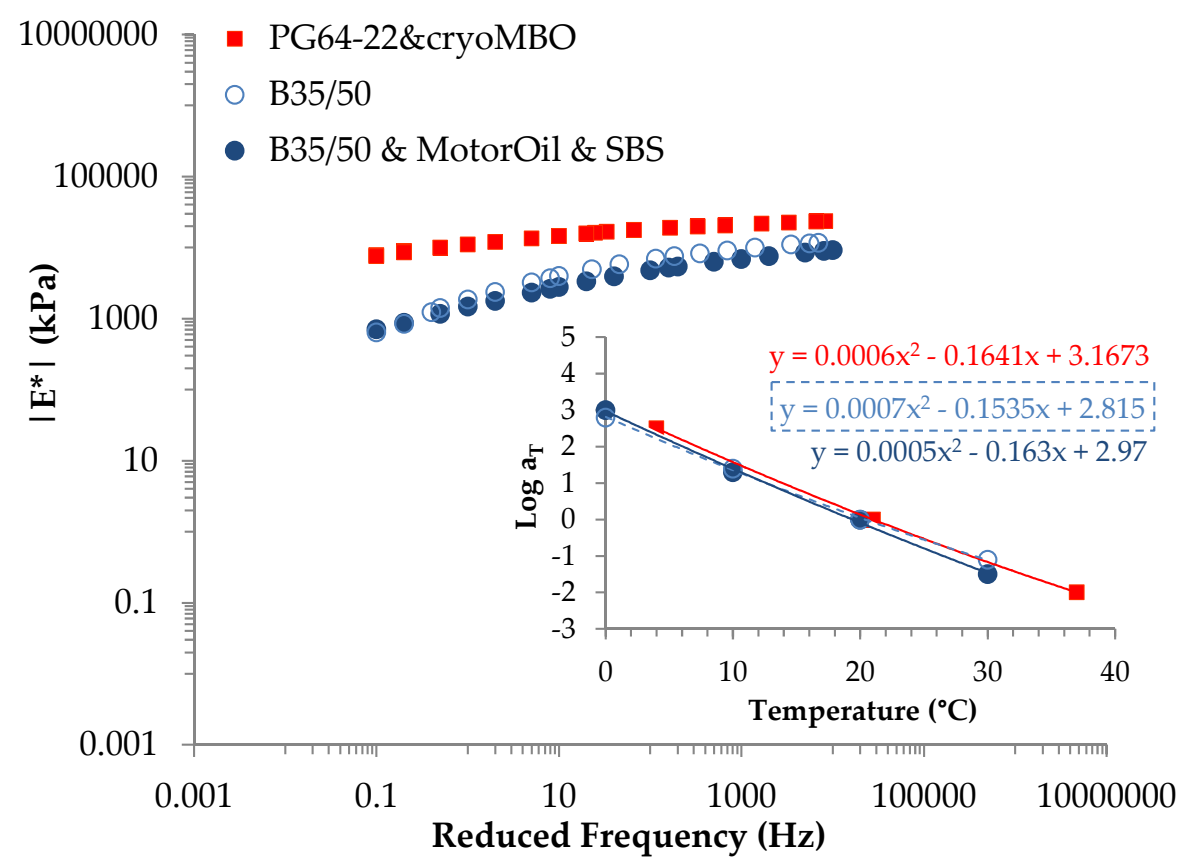

Figure 4. Master curves of the shifted dynamic stiffness modulus for the different asphalt mixtures $\left(\mathrm{T}_{\text {ref }}=21^{\circ} \mathrm{C}\right)$ studied in this work (the insert represents the quadratic fitting of the shift factors obtained using the Arrhenius time-temperature superposition principle).

The analysis of the dynamic modulus master curves shows that the asphalt mixture with the waste motor oil and SBS (B35/50 \& MotorOil \& SBS) is softer than that with bio-oil and ground rubber (PG64-22 \& cryoMBO). This result can partially explain the very good fatigue performance previously observed for the new asphalt mixture with waste motor oil and SBS. Furthermore, the stiffness of that mixture (B35/50 \& MotorOil \& SBS) is similar to that of the conventional mixture with B35/50 bitumen, being slightly higher at very low frequencies and high temperatures. Based on these 
results, it can be assumed that the asphalt mixture with bio-oil and GTR should perform better at high temperatures, followed by the mixture with waste motor oil and SBS. The high stiffness modulus at high temperatures (or low frequencies) points towards a high rutting resistance of the asphalt mixtures with modified binders, which is in agreement with the results obtained by other authors $[38,39]$.

Finally, different rutting resistance tests were applied to evaluate the performance of the asphalt mixtures with modified binders, as previously mentioned in Section 2.2.2. In this particular study, the rutting resistance was obtained by measuring the rut depth formed by successive passages of a wheel, at a temperature of $50{ }^{\circ} \mathrm{C}$. This test ends after 10,000 load cycles. The wheel-tracking slope in air $\left(\right.$ WTS $\left._{\text {AIR }}\right)$ is the main result of this test used to rank the rutting resistance performance of asphalt mixtures, which is calculated based on the evolution of the permanent deformation of the asphalt mixture with the number of cycles during the last 5000 load cycles in the wheel-tracking test. The results of this test demonstrated a higher rutting resistance for the asphalt mixture with waste motor oil and SBS (B35/50 \& MotorOil \& SBS) in comparison to the conventional asphalt mixture (B35/50), as observed from their final rut values $(2.4 \mathrm{~mm}$ and $5.0 \mathrm{~mm}$, respectively). Moreover, the new asphalt mixture with waste motor oil and SBS exhibited a very low WTS $_{\text {AIR }}$ value $\left(0.05 \mathrm{~mm} / 10^{3}\right)$, which confirms the good rutting resistance performance of this mixture in comparison to the conventional asphalt mixture $\left(\mathrm{WTS}_{\mathrm{AIR}}\right.$ value of $\left.0.20 \mathrm{~mm} / 10^{3}\right)$. The rutting resistance of the asphalt mixture with bio-oil and ground rubber (PG64-22 \& cryoMBO), obtained in the previous study [6], was evaluated through the accumulated strain values of the asphalt mixture in a triaxial repeated loading test. The accumulated strain values obtained in that test at $37^{\circ} \mathrm{C}$ and $54{ }^{\circ} \mathrm{C}$ were $0.14 \%$ and $1.00 \%$, respectively. When compared to the conventional asphalt mixture (PG64-22), the results obtained for this mixture with bio-binder are exceptionally good at both temperatures, demonstrating its excellent rutting resistance performance. In conclusion, the very high rutting resistance performance of the asphalt mixtures with modified binders, which is not impaired by the low viscosity of the waste motor oil, confirms the conclusions drawn from the dynamic modulus results.

\section{Conclusions}

The new asphalt binder and mixture evaluated in this work showed that the blend of bitumen, waste motor oil and SBS has better properties than those of conventional bitumen (B35/50), and results in an asphalt mixture with improved performance in comparison to the conventional asphalt mixture.

Actually, the asphalt mixtures with the new modified binders, namely with waste motor oil and SBS (B35/50 \& MotorOil \& SBS) and with bio-oil and ground rubber (PG64-22 \& cryoMBO), showed very good performance in all tests carried out during this study. Thus, a good rutting and fatigue cracking resistance can be expected from these mixtures. In addition, these mixtures are not sensitive to moisture, and their durability can be assured. In particular, the asphalt mixture with waste motor oil and SBS showed a higher fatigue cracking resistance, while the mixture with bio-oil and ground rubber presented higher stiffness and rutting resistance, but both mixtures generally performed well during the laboratorial study. It also becomes clear that the new mixture with waste motor oil and SBS performs better than the conventional mixture B35/50.

The very good performance of the new binders and mixtures with waste-derived oils and elastomer modifiers made the potential of these economical and environmentally friendly solutions to be used in real road pavements even more evident. It should be noted that these solutions should now be applied and evaluated in a real pavement trial, in order to have these alternative binders and mixtures validated by road administrations and ready to be applied by the paving industry.

Acknowledgments: The authors gratefully acknowledge the funding provided by the Portuguese Government (Portuguese Foundation for Science and Technology) and by the Competitiveness Factors Operational Programme (EU/ERDF funds), through the FCT project PLASTIROADS (PTDC/ECM/119179/2010) and the PhD grant SFRH/BD98379/2013. Authors also want to acknowledge all companies mentioned in this document for supplying all the materials, which were essential to obtain the final results presented in this paper. 
Author Contributions: Sara Fernandes (S.F.), Joana Peralta (J.P.), Joel Oliveira (J.O.), Christopher Williams (C.W.) and Hugo Silva (H.S.) conceived and designed the experimental work; S.F and J.P. performed the experiments mentioned in the paper; S.F., J.P., J.O., C.W. and H.S. analyzed the data and contributed to the completion of the manuscript.

Conflicts of Interest: The authors declare no conflict of interest.

\section{References}

1. Costa, L.M.B.; Silva, H.M.R.D.; Oliveira, J.R.M.; Fernandes, S.R.M. Incorporation of waste plastic in asphalt binders to improve their performance in the pavement. Int. J. Pavement Res. Technol. 2013, 6, 457-464.

2. Anastasiou, E.K.; Liapis, A.; Papayianni, I. Comparative life cycle assessment of concrete road pavements using industrial by-products as alternative materials. Resour. Conserv. Recycl. 2015, 101, 1-8. [CrossRef]

3. Costa, L.; Peralta, J.; Oliveira, J.; Silva, H. A New Life for Cross-Linked Plastic Waste as Aggregates and Binder Modifier for Asphalt Mixtures. Appl. Sci. 2017, 7, 603. [CrossRef]

4. Metwally, M.A.R.M.; Williams, R.C. Development of Non-Petroleum Based Binders for Use in Flexible Pavements (Final Report); Institute for Transportation Iowa State University: Ames, IA, USA, 2010.

5. Fuentes-Audén, C.; Martínez-Boza, F.J.; Navarro, F.J.; Partal, P.; Gallegos, C. Formulation of new synthetic binders: Thermo-mechanical properties of recycled polymer/oil blends. Polym. Test. 2007, 26, 323-332. [CrossRef]

6. Peralta, J.; Williams, R.C.; Silva, H.M.R.D.; Machado, A.V.A. Recombination of asphalt with bio-asphalt: Binder formulation and asphalt mixes application. Asph. Paving Technol. Assoc. Asph. Paving Technol. 2014, 83, 1-36.

7. Kowalski, K.; Król, J.; Bańkowski, W.; Radziszewski, P.; Sarnowski, M. Thermal and Fatigue Evaluation of Asphalt Mixtures Containing RAP Treated with a Bio-Agent. Appl. Sci. 2017, 7, 216. [CrossRef]

8. Raouf, M.A.; Williams, R.C. General rheological properties of fractionated switchgrass bio-oil as a pavement material. Road Mater. Pavement Des. 2010, 11, 325-353. [CrossRef]

9. Peralta, J.; Williams, R.C.; Rover, M.; Silva, H.M.R.D. Development of a rubber-modified fractionated bio-oil for use as noncrude petroleum binder in flexible pavements. Transp. Res. Board 2012.

10. Dedene, C.; Mills-Beale, J.; You, Z. Properties of recovered asphalt binder blended with waste engine oil: A preliminary study. In ICCTP 2011: Towards Sustainable Transportation Systems, Proceedings of the 11th International Conference of Chinese Transportation Professionals, Nanjing, China, 14-17 August 2011; ASCE Libarary: Reston, VA, USA, 2011; pp. 4399-4406.

11. DeDene, C.D.; You, Z. The performance of aged asphalt materials rejuvenated with waste engine oil. Int. J. Pavement Res. Technol. 2014, 7, 145-152.

12. Silva, H.M.R.D.; Oliveira, J.R.M.; Jesus, C.M.G. Are totally recycled hot mix asphalts a sustainable alternative for road paving? Resour. Conserv. Recycl. 2012, 60, 38-48. [CrossRef]

13. Lesueur, D. The colloidal structure of bitumen: Consequences on the rheology and on the mechanisms of bitumen modification. Adv. Colloid Interface Sci. 2009, 145, 42-82. [CrossRef] [PubMed]

14. Kuczenski, B.; Geyer, R.; Zink, T.; Henderson, A. Material flow analysis of lubricating oil use in California. Resour. Conserv. Recycl. 2014, 93, 59-66. [CrossRef]

15. Jia, X.; Huang, B.; Bowers, B.F.; Zhao, S. Infrared spectra and rheological properties of asphalt cement containing waste engine oil residues. Constr. Build. Mater. 2014, 50, 683-691. [CrossRef]

16. Yildirim, Y. Polymer modified asphalt binders. Constr. Build. Mater. 2007, 21, 66-72. [CrossRef]

17. Ahmedzade, P. The investigation and comparison effects of SBS and SBS with new reactive terpolymer on the rheological properties of bitumen. Constr. Build. Mater. 2013, 38, 285-291. [CrossRef]

18. Moretti, L.; Di Mascio, P.; D'Andrea, A. Environmental Impact Assessment of Road Asphalt Pavements. Mod. Appl. Sci. 2013, 7. [CrossRef]

19. Moretti, L.; Mandrone, V.; D'Andrea, A.; Caro, S. Comparative "from Cradle to Gate" Life Cycle Assessments of Hot Mix Asphalt (HMA) Materials. Sustainability 2017, 9, 400. [CrossRef]

20. Fernandes, S.; Costa, L.; Silva, H.; Oliveira, J. Effect of incorporating different waste materials in bitumen. Ciênc. Tecnol. Mater. 2017, 29, e204-e209. [CrossRef]

21. Bitumen and Bituminous Binders. Determination of Complex Shear Modulus and Phase Angle. Dynamic Shear Rheometer (DSR); EN 14770; European Commitee for Standardization: Brussels, Belgium, 2012. 
22. Bitumen and Bituminous Binders. Determination of Dynamic Viscosity of Bituminous Binder Using a Rotating Spindle Apparatus; EN 13302; European Commitee for Standardization: Brussels, Belgium, 2010.

23. Bituminous Mixtures. Material Specifications. Asphalt Concrete; EN 13108-1; European Commitee for Standardization: Brussels, Belgium, 2006.

24. Bituminous Mixtures-Test Methods for Hot Mix Asphalt_Part 34: Marshall Test; EN 12697-34; European Commitee for Standardization: Brussels, Belgium, 2012.

25. Asphalt Institute. Superpave ${ }^{\circledR}$ : Performance Graded Asphalt Binder Specification and Testing, 3rd ed.; Asphalt Institute: Lexington, KY, USA, 2003.

26. Resistance of Compacted Bituminous Mixture to Moisture Induced Damage; AASHTO T 283-07; American Association of State Highway \& Transportation Officials: Washington, DC, USA, 2007.

27. Standard Method of Test for Determining the Fatigue Life of Compacted Hot-Mix Asphalt (HMA) Subjected to Repeated Flexural Bending; AASHTO T 321-07; American Association of State Highway \& Transportation Officials: Washington, DC, USA, 2007.

28. Standard Method of Test for Determining the Dynamic Modulus and Flow Number for Hot Mix Asphalt (HMA) Using the Asphalt Mixture Performance Tester (AMPT); AASHTO TP 79-10; American Association of State Highway \& Transportation Officials: Washington, DC, USA, 2010.

29. Bituminous Mixtures_Test Methods for Hot Mix Asphalt_Part 22: Wheel Tracking; EN 12697-22; European Commitee for Standardization: Brussels, Belgium, 2012.

30. Read, J.; Whiteoak, D.; Bitumen, S. The Shell Bitumen Handbook; Thomas Telford: London, UK, 2003.

31. Lottman, R.P. Predicting Moisture-Induced Damage to Asphaltic Concrete Field Evaluation (No. 246); Transportation Research Board: Washington, DC, USA, 1982.

32. Asphalt Institute. Superpave ${ }^{\circledR}$ Mix Design, 3rd ed.; Asphalt Institute: Lexington, KY, USA, 2001.

33. Roberts, F.L.; Kandhal, P.S.; Brown, E.R.; Lee, D.-Y.; Kennedy, T.W. Hot Mix Asphalt Materials, Mixture Design and Construction; Transportation Research Board: Lanham, MD, USA, 1996; p. 603.

34. Brown, E.R.; Kandhal, P.S.; Roberts, F.L.; Kim, Y.R.; Lee, D.-Y.; Kennedy, T.W. Hot Mix Asphalt Materials, Mixture Design, and Construction; National Asphalt Pavement Association Research and Education Foundation: Lanham, MD, USA, 2009.

35. Shell. Shell Pavement Design Manual: Asphalt Pavements and Overlays for Road Traffic; Shell International Petroleum Co. Ltd.: London, UK, 1978.

36. Pais, J.C.; Pereira, P.A.A.; Minhoto, M.J.C.; Fontes, L.P.T.L.; Kumar, D.S.N.V.A.; Silva, B.T.A. The prediction of fatigue life using the $\mathrm{K}_{1}-\mathrm{K}_{2}$ relationship. In 2nd Workshop on Four Point Bending; Pais, J.C., Ed.; University of Minho: Guimarães, Portugal, 2009.

37. Garcia, G.; Thompson, M. HMA Dynamic Modulus Predictive Models-A Review; National Technical Information Service: Alexandria, VA, USA, 2007.

38. Williams, R.C.; Cascione, A.; Haugen, D.S.; Buttlar, W.G.; Bentsen, R.A.; Behnke, J. Characterization of Hot Mix Asphalt Containing Post-Consumer Recycled Asphalt Shingles and Fractionated Reclaimed Asphalt Pavement; Final Report; Illinois State Toll Highway Authority: Downers Grove, IL, USA, 2011.

39. West, R.; Willis, J.R.; Marasteanu, M.O. Improved Mix Design, Evaluation, and Materials Management Practices for Hot Mix Asphalt with High Reclaimed Asphalt Pavement Content; Report No. 752; National Cooperative Highway Research Program, Transportation Research Board of The National Academies: Washington, DC, USA, 2013.

(C) 2017 by the authors. Licensee MDPI, Basel, Switzerland. This article is an open access article distributed under the terms and conditions of the Creative Commons Attribution (CC BY) license (http:/ / creativecommons.org/licenses/by/4.0/). 